things had ever before been heard of, mosquitonetting on all windows, cleared drains and oiled swamps, an enormous increase in the production and use of vaccines. This can only have been possible through the full confidence and co-operation of the masses of the ordinary country people-necessary also for putting into practice the lessons which resulted from the work of the Chilu-Yenching group to which the author belonged. How good it would be if he could visit China again (as I feel sure he would wish), to see and advise on these applications in practice.

JOSEPE NEEDHAM

\section{TREE-SPOTTING IN MALAYA}

\section{Wayside Trees of Malaya}

By E. J. H. Corner. Second edition. Vol. 1 : Text. Pp. vii +772 . Vol. 2 : Plates. Pp. $v+228$ plates $+\mathrm{v}$. (Singapore: Government Printing Office, 1952.) 2 vols., 25 Malay dollars.

THAT a second edition of "Wayside Trees of

Malaya" has been found necessary after a lapse of twelve years-five of them war years when sales must have been very low-is a measure of its popularity. This is not surprising, since if ever there was a book which made easy the path of getting to know the trees, this is it.

The book is divided into two volumes, of which Vol. 1 has four parts. Part 1 contains short discourses on the morphology of the various parts of the trees, shapes of the trees, ant-trees and buttress-trees, phenology, a sketch of the Malayan vegetation, and a valuable list of outstanding trees and where examples of these are to be found.

An elaborate set of keys to the families and some genera, largely based upon vegetative characters, with the subsidiary aid of colour of the latex, and flowers and fruits, makes up Part 2. So far as the reviewer has tested them, these keys are adequate, and demonstrate vividly how far one can proceed on the road to identification without flowering and fruiting characters. These keys look simple; but the knowledge upon which they are based is not picked up in books but is the accumulation of experience gained from many hours spent in the field, often at that time of day when "mad dogs and Englishmen" are the only figures in sight. These keys will sometimes fail, as all keys with a limited objective must fail; but we feel that this will be due to a tree not being a true wayside tree, rather than that the key is at fault.

Part 3 includes the families arranged in alpha. betical order. Under each family is a key to the genera, and under each genus a key to the species. These keys are kept as simple as possible consistent with adequacy. The text is liberally sprinkled with line sketches by the author of those parts of the plant which aid identification. The text itself is no mere collection of botanical data, but more often gives the biological life of the plant, its phenology, its synecology, pollination, folk-lore, and so on. Part 4 is taken up with the indexes.

Vol. 2 consists entirely of 228 half-tone plates, the great majority of which are of outstanding merit. These consist of tree portraits and photographs of leaves and flowers or fruits, or both, and are a valuable aid in identification.

The weight of the two volumes is about $5 \frac{1}{2} \mathrm{lb}$., which certainly makes the work difficult to carry about. But presumably, in Malaya every potential buyer possesses a vehicle of some sort, so that perhaps this is not the drawback it would be, for example, in Great Britain.

Dr. Corner and the Government Press, Singapore, are to be congratulated on the production of a really useful book. One would like to know how the Press contrived to produce this well-bound, beautifully printed book of 772 pages and 228 half-tone plates at the extremely reasonable price of just under $\mathfrak{£ 3}$.

N. L. Bor

\section{A TRUANT FROM THE PSYCHOANALYTICAL SCHOOL}

The Psychology and Psychotherapy of Otto Rank An Historical and Comparative Introduction. By Dr. Fay B. Karpf. Pp. xii $+129+3$ plates. (New York : Philosophical Library, Inc., 1953.) 3 dollars.

THIS book is not only a description of Rank's contribution to psychology, but is also an attempt to place him on the same footing as Jung and Adler with regard to Freud. This is unfortunate, since he remained an adherent of the psychoanalytical school until the age of forty-two, and his early death at fifty-five gave him little time to produce enough original work upon which to base a solid reputation after he broke away. In fact, although the author denies it, Rank is an example of Brill's statement that "Reflecting on the works of the Freudian secessionists, I feel that none of them has contributed anything of real value to mental science since they separated themselves from the master". It is, of course, an exaggeration but has some basis of truth.

Rank was more interested in the cultural aspects of psychoanalysis, and this is reflected in his workas shown in "The Artist", "The Myth of The Birth of The Hero", etc.--an innovation from the point of view of sociology but not of much use clinically. In fact, it is doubtful whether any of his psychotherapeutic devices are of any value. He claimed to abbreviate treatment by fixing a terminal date for it, but this has not been found successful, and his "Will Therapy" seems aimed at conscious rather than unconscious elements. Dr. Fay B. Karpf does not make the most of the very real contributions to theory which Rank did make and, in discussing the trauma of birth, becomes side-tracked in a discussion on "masculine inferiority" and "womb envy" instead of using it to show how far back analysis may be forced.

This book is not an easy one to read : it is prolix, verbose and often difficult to understand. Such sentences as this one (from p. 75) abound: "Unlike the will concept which Rank took over as an organizing concept from the fields of psychology and philosophy after he became sensitized to the therapeutic manifestations of will phenomena, he arrived at the relationship concept directly from his therapeutic observation and experience and his consequent attempt to reinterpret the psychoanalytic conception of transference in terms of mother-centred dependency". Anyone interested in Rank and willing to labour through the complicated prose will find this book of interest; but it will not be of value to the general reader of psychology. The paper and printing are excellent; there are a good bibliography and a seven-page index.
CLIFFORD AltiEN 